\title{
ОЦЕНКА И ПРАВОВОЕ РЕГУЛИРОВАНИЕ ПРОЕКТОВ РАЗВИТИЯ ТЕРРИТОРИИ
}

\section{Андрей Андреевич Бибик}

Сибирский государственный университет геосистем и технологий, 630108, Россия, г. Новосибирск, ул. Плахотного, 10, обучающийся, тел. (983)151-95-66, e-mail: and.bibik98@yandex.ru

\section{Александр Сергеевич Федорчук}

Сибирский государственный университет геосистем и технологий, 630108, Россия, г. Новосибирск, ул. Плахотного, 10, обучающийся, тел. (905)950-39-05, e-mail: sasha.fedorchuk.2014@mail.ru

\section{Анна Олеговна Ткаченко}

Сибирский государственный университет геосистем и технологий, 630108, Россия, г. Новосибирск, ул. Плахотного, 10, кандидат экономических наук, доцент кафедры цифровой экономики и менеджмента, тел. (383)361-01-24, e-mail:sizovaao@yandex.ru

Проекты комплексного развития территории рассматривают строительство объектов, соответствующих документации по планировке территории. Планирование проектов развития территории осуществляется в рамках регулируемого правового поля. Несогласованность направлений развития, указанных в основных Федеральных законах и стратегии социальноэкономического развития города Новосибирск порождает проблемы удовлетворения нужд населения рассматриваемой территории.

Ключевые слова: проекты развития территории, планировка жилых районов, застройка земельных участков, цели развития субъекта

\section{ASSESSMENT AND LEGAL REGULATION OF TERRITORIAL DEVELOPMENT PROJECTS}

\section{Andrey A. Bibik}

Siberian State University of Geosystems and Technologies, 10, Plakhotnogo St., Novosibirsk, 630108, Russia, Student, phone: (983)151-95-66, e-mail: and.bibik98@yandex.ru

\section{Alexandr S. Fedorchuk}

Siberian State University of Geosystems and Technologies, 10, Plakhotnogo St., Novosibirsk, 630108, Russia, Student, phone: (905)950-39-05, e-mail: sasha.fedorchuk.2014@mail.ru

\section{Anna O. Tkachenko}

Siberian State University of Geosystems and Technologies, 10, Plakhotnogo St., Novosibirsk, 630108, Russia, Ph. D., Associate Professor, Department of Digital Economy and Management, phone: (383)361-01-24, e-mail:sizovaao@yandex.ru

Complex development projects of the territory consider the construction of facilities, corresponding to documentation for the planning of the territory. Territory development projects are planned in a regulated legal framework. The inconsistency in the use of the development specified in the basic federal laws and the strategy of economic development of Novosibirsk gives rise to meeting the needs of the population of the territory under consideration.

Keywords: development projects of the territory, layout of the rear part, development of land plots, development goals of the subject 


\section{Введение}

В 1930-х годах началась застройка земельных участков, которые были выделены под строительство. Как любой крупномасштабный проект, застройка земельных участков характеризуется правовым режимом и нормативными документами развития территории.

\section{Актуальность и степень проработанности темы}

Актуальность данной темы заключается в том, что при правовом регулировании развития территории стоит задача не только расширения масштабов и повышения темпов роста застроенных территорий города с точки зрения планировки жилых районов, но и учета экономического аспекта развития города, его архитектурной привлекательности, что будет способствовать эффективному использованию бюджетных средств и средств инвесторов.

Проблема эффективного планирования развития территории обусловлена возникновением построек-долгожителей, которые существенное время могут не эксплуатироваться и занимать территорию, предназначенную для более перспективных построек, повышающих привлекательность общего облика города.

Цель исследования: анализ нормативно-правовых актов, регулирующих деятельность строительных и инвестиционных компаний в сфере комплексного освоения территорий.

Правовое регулирование процедуры создания развития территории отталкивается от двух Федеральных законов [4]:

- Федеральный закон «Об особых экономических зонах в Российской Федерации» от 22.07.2005 № 116-Ф3;

- Федеральный закон «О территориях опережающего социальноэкономического развития в Российской Федерации» от 29.12.2014 № 473-Ф3.

Основываясь на этих Федеральных законах можно выявить основной принцип процедуры проектирования градостроительной деятельности, которым является развитие территорий. Данный проект должен решать следующие задачи $[4,5]$ :

- грамотное распределение ресурсов государства на сбалансированное развития субъектов РФ;

- стратегически эффективное территориальное расположение объектов, служащих для оздоровительных целей, учреждений рекреационного назначения, предприятий обслуживающих нужды населения в виде социального, культурно-бытового характера, места работы и отдыха;

- выполнение нормативно-правовых актов и соблюдение этих требований в области безопасности территории, инженерно-технических требований, предупреждения о ЧС;

- обеспечение защиты объектов, приравниваемых к культурному наследию и особо охраняемых территорий;

- анализ возможностей освоения подземного пространства. 


\section{Результаты}

Достижение целей проекта градостроительной деятельности, выполняется за счет планомерного развития территории субъектов РФ [4] на основе нормативно-правовых документов территориального планирования, градостроительного зонирования и документации по застройке территории субъекта РФ.

Также при создании проекта развития территории могут допускаться ошибки в виде целей, которые не будут удовлетворять развитию субъекта или нужд населения. Расхождения проектов развития территории и нужд населения обусловлено несогласованностью требований основных Федеральных законов и стратегии социально-экономического развития города Новосибирска $[6,8]$, что оказывает влияние на качество жизни населения.

Основываясь на оценке практики проектной деятельности по развитию территорий г. Новосибирск можно рассмотреть ряд примеров несогласованности. Летом 2017 года проводился опрос жителей г. Новосибирск, проживающих на ул. Ипподромной и Красном проспекте на тему «Реконструкция зоны Ельцовки-1». Данная территория оказалась очень востребованной в Центральном районе и заняла первое место в рейтинге общественных территорий. Жители проголосовали за создание парка отдыха. Осенью 2017 в Новосибирске проходил конкурс «125 идей для Новосибирска». Идея создания парковой зоны в пойме реки Ельцовка-1 стала призером конкурса. Овраг реки Ельцовка-1 достаточно широк для строительства парка, что представлено на рис. 1, но в плане указана иная цель использования - строительство автомобильной магистрали, а также увеличение жилой застройки, дополнительные автостоянки и объекты инженерной инфраструктуры [10].

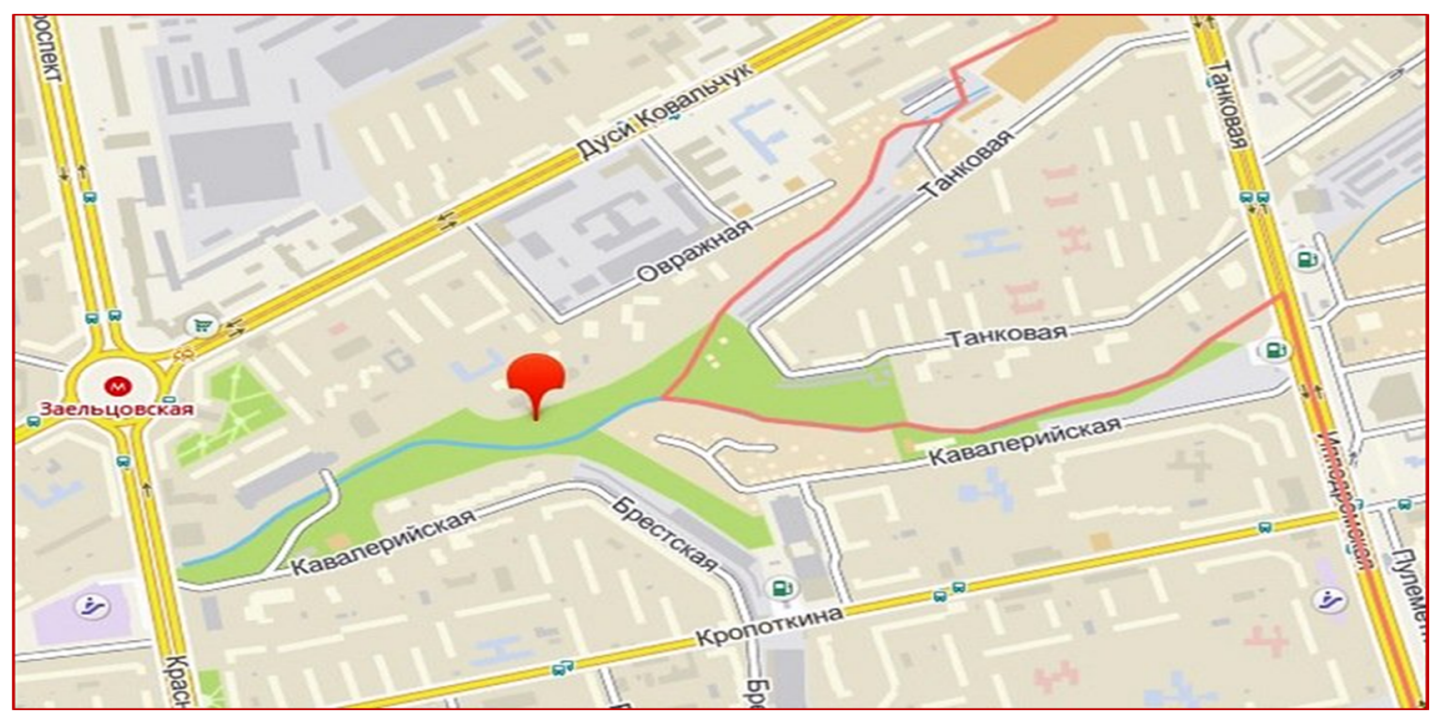

Рис. 1. Местоположение реки

Предварительные расчеты показывают, что 40 тысяч жителей проживают в небольшом радиусе от речки равном 500 метрам, а ближайшие парки с оздоровительным и реакционным функционалом находятся на расстоянии 1,5 км. 
На рисунке 2 представлен макет будущего парка. Можно сделать вывод, что для жителей недостаточно мест отдыха. Вокруг оврага находятся крупные и оживленные автомагистрали - Красный проспект, улица Дуси Ковальчук, Ипподромская магистраль. Строительство новой ветки магистрали не улучшит проблему с дорожным движением, усугубляя экологию города и рассматриваемого района: увеличение количества пыли и взвесей в воздухе, выхлопных газов, уменьшение содержания свежего воздуха и прирост новых заболеваний. Решением проблемы загруженности дорожной сети является развитие общественного транспорта.

Также стоит отметить, что проживающие в этом районе жители были против строительства новой магистрали поверх речки, они пытались добиться присвоения статуса рекреационной зоны пойме реки Ельцовка-1, для дальнейшего финансирования проектов по обустройству нового парка.

Сейчас территория парка условна: его границы не зафиксированы в кадастре, но выдано разрешение на использование территории в целях благоустройства.

Примечательно, что в целом все участники заседания - и эксперты, и чиновники, и общественники - выступили за создание парка, но решение о начале строительства первого этапа не было принято.

К разработке проекта парка в пойме реки Ельцовка-1 общей площадью порядка 10 га был подготовлен проект обустройства. Автор проекта - архитектурная мастерская «Адаптик-А»; соавторы проекта реконструкции Михайловской набережной. Заказчик проекта - ГК «Химметалл», дочерняя компания которой владеет участком в месте слияния двух рукавов реки в 1,5 га земли. Треть площади должны занять два жилых дома (их уже начали строить), а две трети компания предполагала благоустроить и передать городу как первый этап строительства Ельцовского парка.

Из всего вышесказанного следует, что возведение парка на реке Ельцовка-1 будет одним из лучших вариантов благоустройства городской территории, чем создание будущей автомагистрали, где отсутствует инфраструктура. Население данной территории сможет получить доступ к новому парку, проводить свой досуг с пользой $[7,9]$. В Новосибирске на данный момент возведено 9 парков культуры и отдыха, сможет появиться 10-ый парк, также он станет 4-ой облагороженной парковой зоной в данном районе.

Реализация проекта развития территорий может осуществиться в соответствии со следующими нормативными актами из Гражданского Кодекса Российской Федерации [3]:

- статья 46.10 Гражданского Кодекса Российской Федерации «Об комплексном развитии территории по инициативе органа местного самоуправления». Эта статья позволяет регламентировать один из видов деятельности по комплексному и устойчивому развитию территории;

- статья 46.9 Гражданского Кодекса Российской Федерации, регламентирующая деятельность по развитию территорий по инициации правообладателей земельных участков и расположения объектов недвижимого имущества. 


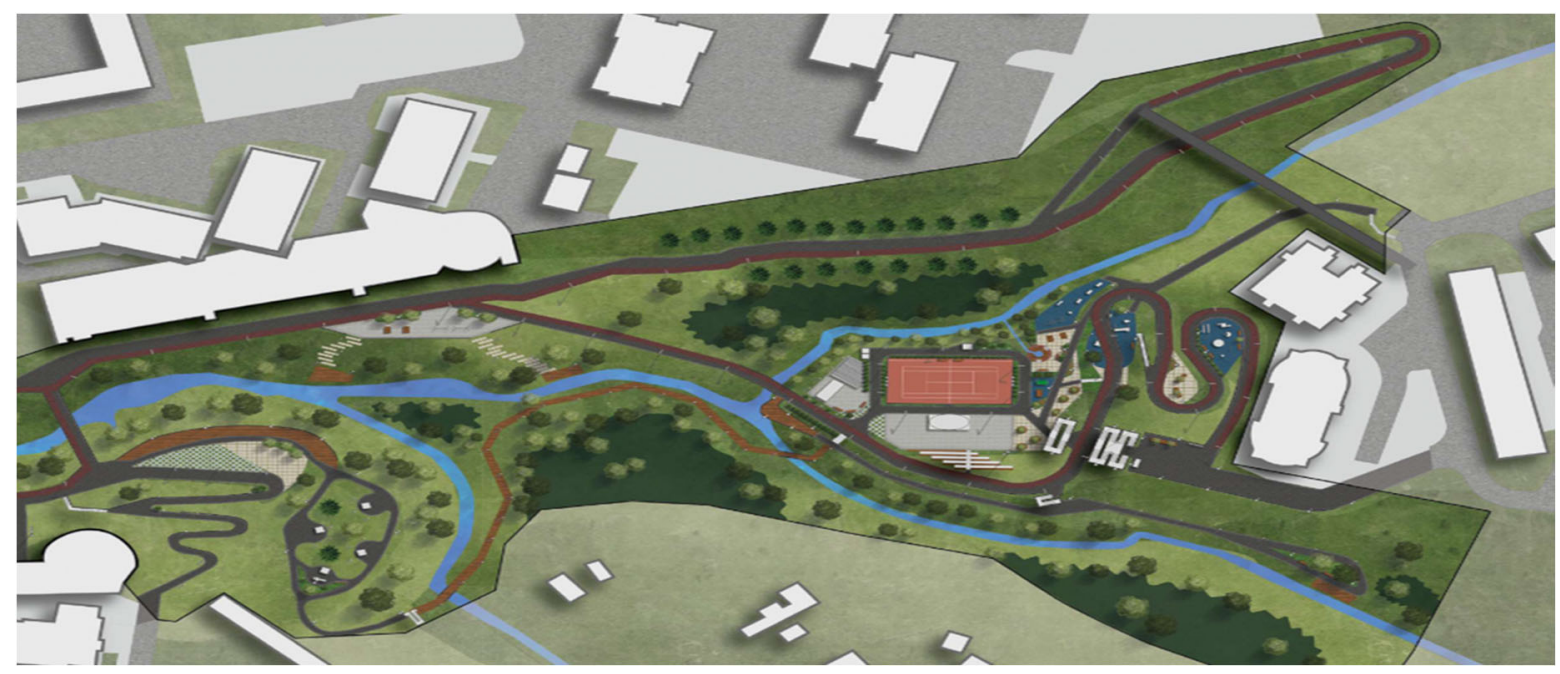

Рис. 2. Макет парка

\section{Заключение}

Для реализации комплексного развития и совершенствования территорий необходимо введение ряда планов градостроительных мероприятий. Обеспечение комфортного для жизнедеятельности состояния определенной зоны проекта в соответствии с Федеральным законом «О территориях опережающего социально-экономического развития в Российской Федерации» от 29.12.2014 № 473-Ф3 гарантируется при создании ряда планов $[1,2]$.

Таким образом, деятельность субъектов Российской Федерации в области правового регулирования процедур создания проекта развития территорий основывается на нормативно-правовых актах, Гражданском Кодексе, Федеральном законе «Об особых экономических зонах в Российской Федерации» от 22.07.2005 № 116-Ф3, Федеральном законе «О территориях опережающего социально-экономического развития в Российской Федерации» от 29.12.2014 № 473-Ф3. На основании чего формируется возможность осуществления разработки крупномасштабных проектов по созданию современной, качественной и комфортной городской среды.

Необходимо отметить, что нормативно-правовые документы территориального планирования должны быть разработаны в соответствии с документами стратегического социально-экономического планирования территорий. Coгласование вышеназванных документов должно учитываться каждым уровнем организации публичной власти.

\section{БИБЛИОГРАФИЧЕСКИЙ СПИСОК}

1. Аралбаева, Ф. З. Инновационно-ориентированный подход в обеспечении социальноэкономического развития сельских территорий муниципальных образований [Текст] : монография / Ф. З. Аралбаева, Д. Н. Тимофеев, А. П. Цыпин ; М-во образования и науки Российской Федерации, Федеральное гос. бюджетное образовательное учреждение высш. проф. образования «Оренбургский гос. ун-т». - Оренбург : Университет, 2013. - 97 с.

2. Асатрян А. Г. Формирование, развитие и управление инновационной инфраструктурой города : автореферат дис. ... кандидата экономических наук : 08.00.05 / Асатрян Ануш Гагиковна; [Место защиты: Гос. акад. проф. переподготовки и повышения квалификации руководящих работников и специалистов инвестиц. сферы]. - М.: 2010. - 24 с. 
3. Бадмажапова, Ж.Э. Теоретические основы стратегического планирования развития региональных отраслевых систем // Ж.Э. Бадмажапова. - Вестник Забайкальского государственного университета. М.: 2016. - 75 с.

4. Белякова Е.А., Юрова В.С. Нормативно-правовое регулирование в сфере комплексного освоения территории // Е.А. Белякова, В.С. Юрова. - Научное обозрение. Экономические науки. - 2019. - № 2 - С. 33-37.

5. Градостроительный кодекс Российской Федерации от 29.12.2004 № 190-Ф3 (ред. от 03.08.2018) (с изм. и доп., вступ. в силу с 13.08.2019) [Электронный ресурс]// М: Официальный сайт «КонсультантПлюс» Режим доступа: https://.consultant.ru (дата обращения 10.11.2020) - Загл. с экрана.

6. Дубровский А.В., Малыгина О.И. Учет экологических факторов при кадастровой оценке земель населенных пунктов [Электронный ресурс] // Тезисы национальной научнопрактической конференции «Регулирование земельно-имущественных отношений: технологические решения, кадастровая оценка, нормативно-правовое обеспечение», 20-22 июня 2018 г. - Томск: ТГАСУ, 2018. - С. 19. - Режим доступа: http://www.tsuab.ru/upload/files/ additional/SBORNIK_konferencii_file_6478_5585_4145.pdf.

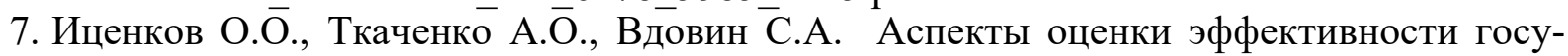
дарственных региональных программ // О.О. Иценков, А.О. Ткаченко, С.А. Вдовин. Вестник Белгородского университета кооперации, экономики и права. Вып 4(83), 2020. С. 65 - 74.

8. Решение совета депутатов города Новосибирска № 726 от 24 декабря 2018 г. «О стратегии социально-экономического развития города Новосибирска на период до 2030 года и признании утратившими силу отдельных решений городского совета Новосибирска, Совета депутатов города Новосибирска» [Электронный ресурс]. М., [2020]. - Режим доступа: https://novo-sibirsk.ru/upload/iblock/eaf/2018_resh_726.pdf. (дата обращения 09.11,2020) - Загл. с экрана.

9. Смирнова О. О. Правовые основы стратегического планирования в Российской Федерации // Контуры глобальных трансформаций: политика, экономика, право. 2012. №2 (22). URL: $\quad$ https://cyberleninka.ru/article/n/pravovye-osnovy-strategicheskogo-planirovaniya-vrossiyskoy-federatsii (дата обращения: 11.11.2020).

10. Сущенцева, Н.В. Вопросы территориального планирования. Учебно-методическое пособие / Псарев, В.И., Гончаров, И.А. - М: Сибирское книжное издательство, 2016. - 123 с.

(C) А. А. Бибик, А. С. Федорчук, А. О. Ткаченко, 2021 